\title{
The emergence of Taenia solium cysticercosis in Eastern and Southern Africa as a serious agricultural problem and public health risk
}

Isaac K. Phiri ${ }^{\mathrm{a}, *}$, Helena Ngowi ${ }^{\mathrm{b}}$, Sonia Afonso ${ }^{\mathrm{c}}$, Elizabeth Matenga ${ }^{\mathrm{d}}$, Mathias Boa ${ }^{b}$, Samson Mukaratirwa ${ }^{d}$, Samuel Githigia ${ }^{e}$, Margaret Saimo ${ }^{f}$, Chummy Sikasunge a, Ndichu Maingi e, George W. Lubega ${ }^{f}$, Ayub Kassuku ${ }^{b}$, Lynne Michael $^{\mathrm{g}}$, Seter Siziya ${ }^{\mathrm{h}}$, Rosina C. Krecek ${ }^{\mathrm{i}}$, Emilia Noormahomed ${ }^{\mathrm{j}}$, Manuela Vilhena ${ }^{\mathrm{k}}$, Pierre Dorny ${ }^{1}$, A. Lee Willingham III ${ }^{\mathrm{m}}$

${ }^{\text {a }}$ School of Veterinary Medicine, University of Zambia, Lusaka, Zambia

${ }^{\mathrm{b}}$ Department of Veterinary Microbiology and Parasitology, Faculty of Veterinary Medicine, Sokoine University of Agriculture, Morogoro, Tanzania

${ }^{\mathrm{c}}$ Faculdade de Veterinária, Universidade Eduardo Mondlane, Maputo, Mozambique

${ }^{\mathrm{d}}$ Faculty of Veterinary Science, University of Zimbabwe, Mt. Pleasant, Harare, Zimbabwe

${ }^{\mathrm{e}}$ Department of Veterinary Pathology, Microbiology and Parasitology, Faculty of Veterinary Medicine, University of Nairobi, Nairobi, Kenya

${ }^{\mathrm{f}}$ Faculty of Veterinary Medicine, Makerere University, Kampala, Uganda

g Division of Parasitology, Onderstepoort Veterinary Institute, Onderstepoort, South Africa

${ }^{\mathrm{h}}$ School of Medicine, University of Zambia, Lusaka, Zambia

${ }^{\mathrm{i}}$ Department of Zoology and Entomology, Faculty of Natural and Agricultural Sciences, University of Pretoria, Pretoria, South Africa

${ }^{\mathrm{j}}$ Faculdade de Medicina, Universidade Eduardo Mondlane, Maputo, Mozambique

${ }^{\mathrm{k}}$ Universidade de Évora, Evora, Portugal

${ }^{1}$ Department of Animal Health, Prince Leopold Institute of Tropical Medicine, Antwerp, Belgium

${ }^{\mathrm{m}}$ WHOIFAO Collaborating Centre for Parasitic Zoonoses, Danish Centre for Experimental Parasitology, Department of Veterinary Microbiology, Royal Veterinary and Agricultural University, Frederiksberg, Denmark

\begin{abstract}
Pig production has increased significantly in the Eastern and Southern Africa (ESA) region during the past decade, especially in rural, resource-poor, smallholder communities. Concurrent with the increase in smallholder pig keeping and pork consumption, there have been increasing reports of porcine cysticercosis in the ESA region. This article reviews the findings concerning the presence and impact of porcine cysticercosis in seven of the ESA countries. Most of the reported findings are based on surveys utilising lingual palpation and post-mortem examination, however, some also used serological assays. In Tanzania, community-based studies on porcine cysticercosis indicate a prevalence of
\end{abstract}

\footnotetext{
* Corresponding author. Address: Department of Clinical Studies, School of Veterinary Medicine, University of Zambia, P.O. Box 32379 Lusaka, Zambia. Tel.: +260-1-291-190; fax: +260-1-291-190/193-727.

E-mail address: iphiri@vet.unza.zm (I.K. Phiri).
} 
$17.4 \%$ in the northern highlands district of Mbulu and a prevalence range of 5.1-16.9\% in the southern highlands. In Kenya recent surveys in the southwestern part of the country where smallholder pig keeping is popular indicate that $10-14 \%$ of pigs are positive for cysticercosis by lingual examination. Uganda has the most pigs in Eastern Africa, most of which are kept under smallholder conditions. Preliminary surveys in 1998 and 1999 at slaughterhouses in Kampala indicated a prevalence of porcine cysticercosis between 0.12 and $1.2 \%$, however, a rural survey in northern Uganda in 1999 indicated $34-45 \%$ of pigs slaughtered in selected villages were infected. Additionally, a new survey of 297 pigs slaughtered in Kampala in 2002 indicated that pigs from the central region of the country were negative for cysticercosis while $33.7 \%$ of the pigs coming from the rural Lira district in the north were positive. Interestingly, 8 piglet foetuses removed from an infected slaughtered sow coming from Lira district were all found to harbour cysts of T. solium providing evidence of congenital transmission of porcine cysticercosis. In Mozambique, abattoir records indicate that porcine cysticercosis is present in all provinces of the country. A serological survey on pigs in rural Tete Province found $15 \%$ of pigs positive. In Zimbabwe, a retrospective study in official abattoirs around the country from 1994 to 2001 reported a mean prevalence of $0.34 \%$ which is in contrast to a post-mortem survey in 1999 , which showed that the prevalence of porcine cysticercosis in rural west Zimbabwe where smallholder pig keeping is popular was $28.6 \%$. In Zambia, abattoir records reported porcine cysticercosis in six of the nine provinces. Routine meat inspection of 1316 pigs at a slaughter slab in Lusaka showed that $20.6 \%$ of the pigs had cysticercosis whereas serological testing of 874 pigs at the same abattoir indicated that $56.6 \%$ were found to have circulating antigens of Taenia solium. Field surveys based on lingual palpation in Southern and Eastern Provinces of Zambia revealed prevalences of 8.2-28.4 and 5.2\%, respectively. South Africa has the largest number of pigs in Southern Africa and cysticercosis has been recognised as a problem in the country for many decades. There is strong evidence supporting the high prevalence of neurocysticercosis infecting humans from resource-poor areas of the country where pigs are being raised under smallholder conditions. In spite of this community-based surveys on porcine cysticercosis have never been conducted in South Africa and the last slaughterhouse survey was conducted nearly 40 years ago. The prevalences of porcine cysticercosis found in these ESA countries rank among the highest in the world and the disease is emerging as an important constraint for the nutritional and economic well being of resource-poor smallholder farming communities. The current findings suggest the widespread presence of human tapeworm carriers and thus a high risk of human cysticercosis in both rural areas and urban centres in the ESA region. More research is required in the region to assess the extent and public health and economic impact of $T$. solium infection in order to determine whether and what prevention and control efforts are needed.

(C) 2003 Elsevier Science B.V. All rights reserved.

Keywords: Pig; Taenia solium; Porcine cysticercosis; Prevalence; Enzyme-linked immunosorbent assay; Kenya; Uganda; Tanzania; Mozambique; Zambia; Zimbabwe; South Africa

\section{Introduction}

Pig production has increased significantly in the Eastern and Southern Africa (ESA) region during the past decade, especially in rural, resource-poor, smallholder communities (Figs. 1 and 2). The lack of grazing land for ruminants and the recognition by farmers of quicker and higher returns on their investment have contributed to an increased interest in raising pigs. In addition, higher consumer demand for pork in urban areas of the region has resulted in increased market value of pork. Although modern management is on the increase in some countries and communities in the region, the main form of pig keeping is under extensive, free-range conditions though sometimes primitive housing is provided (Figs. 3 and 4). In spite of the greatly increased popularity of consuming pork there is still a general lack of slaughterhouse facilities in the region for pigs and inspection and control of pork is poor or absent. Evidence gathered through research and government surveys in recent years indicates that porcine cysticercosis, caused by the zoonotic tapeworm Taenia solium, is emerging as a significant problem affecting not only smallholder pig production but 


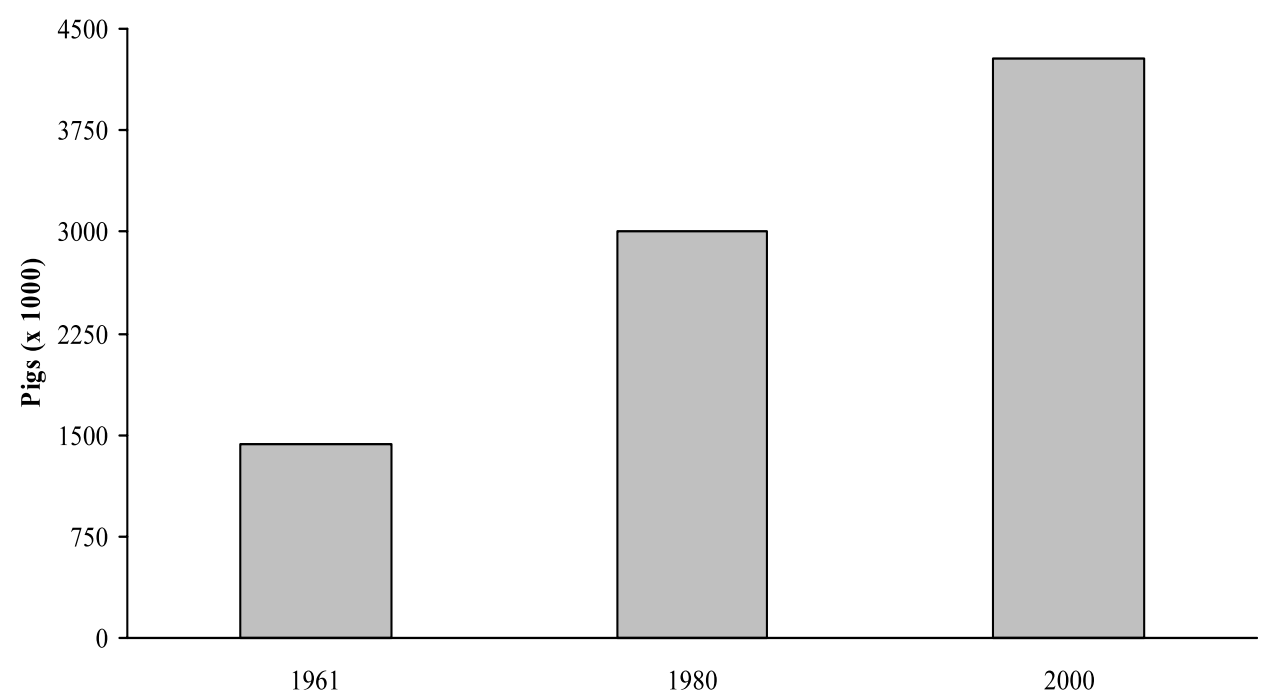

Fig. 1. Trend in the total pig population in the Eastern and Southern Africa countries of Uganda, Tanzania, Kenya, Zambia, Zimbabwe and Mozambique over the past 40 years (FAO, 2002).

also the wellbeing of smallholder farming communities and poses a serious public health risk for the population in general.

Infection with $T$. solium is widely prevalent in human and pig hosts in many developing countries of Latin America, Africa, and Asia (Sarti et al., 1992). Humans are the only natural definitive host while pigs are the intermediate hosts. Man may become an intermediate host from ingestion of eggs of the adult tapeworm, resulting in a condi- tion known as human cysticercosis. The cysticerci of $T$. solium may lodge in the brain causing cerebral cysticercosis (neurocysticercosis), resulting in headache, epileptic seizures, blindness, mental disturbance and even death (White, 2000). The T. solium taeniosis/cysticercosis complex is associated with poor sanitation and hygiene, poor methods of pig husbandry and lack of proper meat inspection and disease control measures. Ingestion of larvae (cysticerci) in raw or

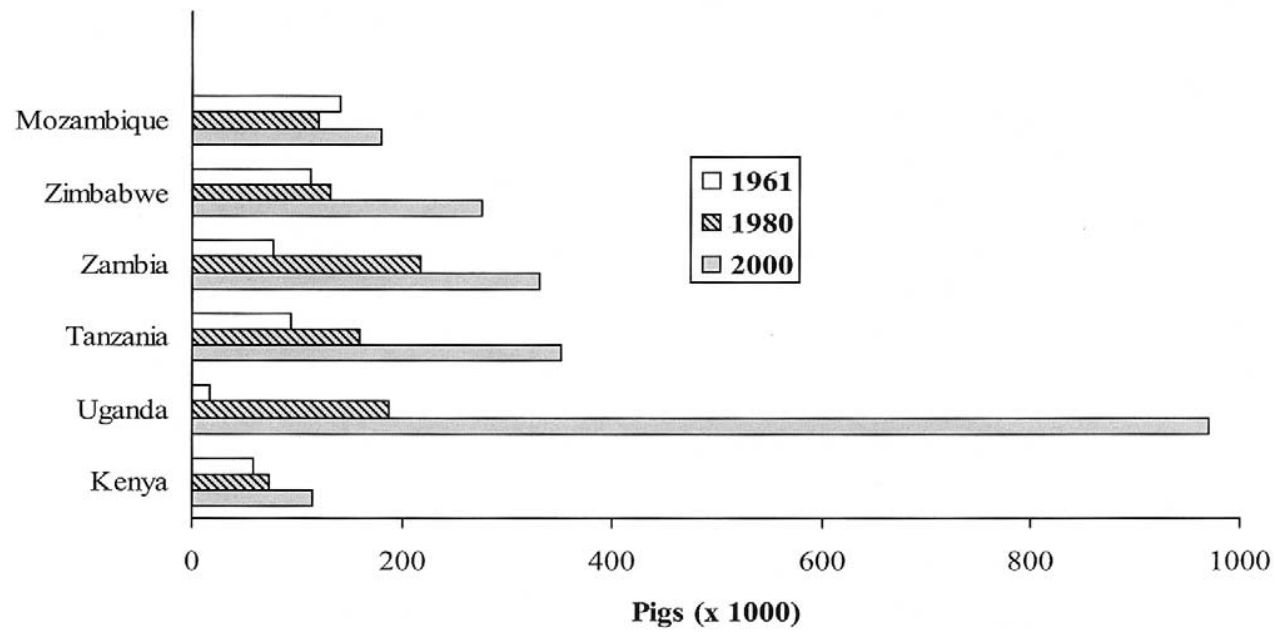

Fig. 2. Trend in pig populations for individual Eastern and Southern Africa countries from 1961-2000 (FAO, 2002). 


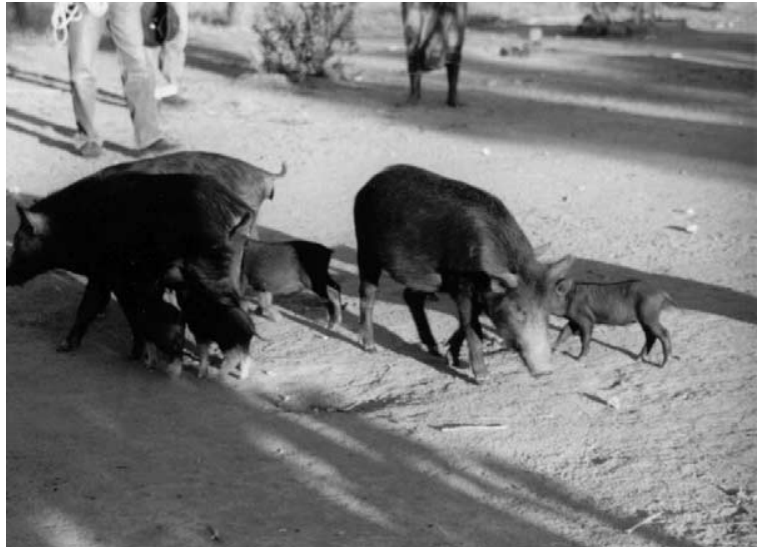

Fig. 3. Smallholder pigs in Eastern and Southern Africa are often allowed to freely roam about to scavenge for food.

inadequately cooked pork results in human tapeworm infection (taeniosis).

Porcine cysticercosis represents one of the most important constraints to increased pig production in the developing world especially affecting the economic and nutritional wellbeing of the rural poor. While this infection has an economic impact due to meat condemnation, the major effect is on public health and the resulting impact on human productivity (Anonymous, 1995). The intent of this paper is to review collectively the current evidence concerning porcine cysticercosis in selected countries of the ESA region (see map in Fig. 5) as a way of initiating documentation of the presence and impact of $T$. solium in the ESA region and increasing awareness of stakeholders at all levels about the issue in order to stimulate more research and hopefully instigate surveillance and control efforts.

\section{Eastern Africa}

\subsection{Tanzania}

Porcine cysticercosis was detected in Eastern Africa in the late 1980s when Tanzanian pigs from the northern highlands district of Mbulu were exported to Kenya and found to be heavily infected with the disease at slaughter. A retrospective study of slaughter slab records from

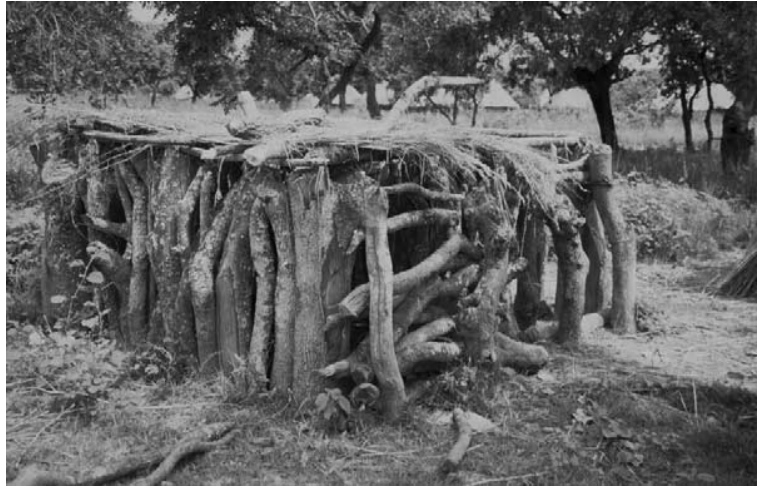

Fig. 4. Smallholder pigs in Eastern and Southern Africa may be provided with housing especially during the crop growing season which may be quite primitive confining adult pigs but often allowing piglets to escape.

Mbulu district in Tanzania from 1985 to 1989 indicates a prevalence increasing from 0.41 to $4.88 \%$ during that time (Nsengwa, 1995). This was further substantiated in 1993 by a postmortem survey of pigs slaughtered at different slaughter slabs in the northern highlands (Arusha, Moshi, Mbulu), which indicated that 4.5-37.7\% were infected, with the vast majority of these pigs originating from Mbulu (Boa et al., 1995). A recent ante-mortem survey involving lingual examination of pigs in villages of Mbulu District revealed an overall district prevalence of $17.4 \%$ $(n=770)$, with a prevalence of the individual villages $(n=21)$ ranging from 3.2 to $46.7 \%$ (Ngowi, 1999). In the southern highlands of Tanzania, where more than $60 \%$ of the country's pigs are raised, a similar ante-mortem study was conducted in the three districts of Iringa, Chunya and Songea during 2001-2002 (M. Boa, Faculty of Veterinary Medicine, Sokoine University of Agriculture, Morogoro, Tanzania, personal communication, 2002). In Chunya the overall district prevalence was $5.5 \%(n=692)$, with prevalence of individual villages ranging from 0 to $21.7 \%$. While in Iringa the overall prevalence was $8.8 \%$ $(n=795)$, with prevalence of individual villages $(n=25)$ ranging from 0 to $26.9 \%$. In Songea the prevalence was $16.9 \%(n=302)$, ranging from 8.0 to $25.0 \%$ in 12 villages. Interviews of people in pig raising communities in both the northern and southern highlands indicate that infection with 


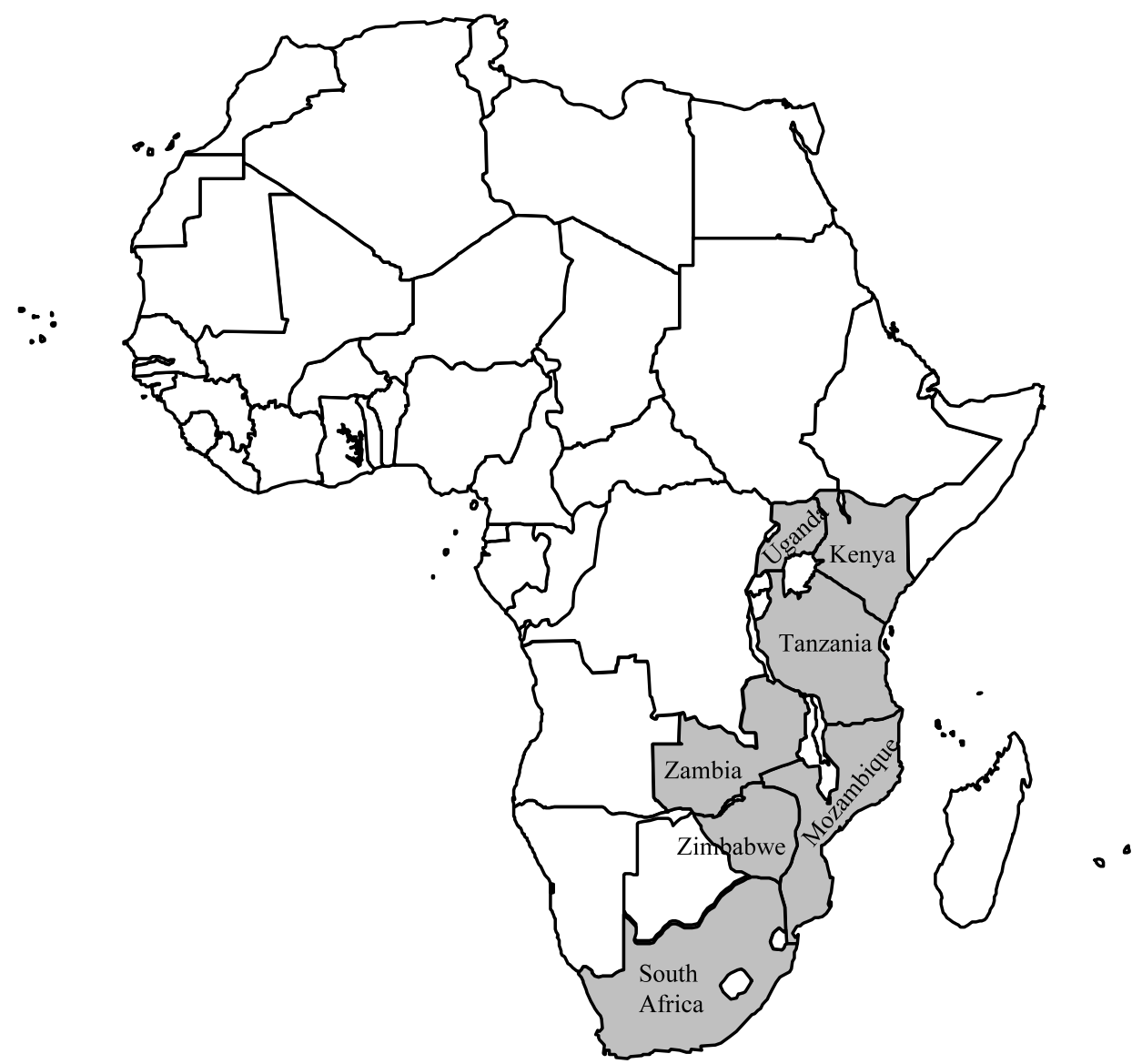

Fig. 5. Location of countries in Eastern and Southern Africa included in the review of porcine cysticercosis.

cysticercosis is becoming a major obstacle for farmers to market their pigs as the pig traders have become aware of the problem and now make pre-purchase examinations in order to determine infection status of the pigs. The vast majority of the farmers are unaware of the mode of transmission of $T$. solium and its zoonotic potential $(\mathrm{H}$. Ngowi, Faculty of Veterinary Medicine, Sokoine University of Agriculture, Morogoro, Tanzania, personal communication, 2002; M. Boa, Faculty of Veterinary Medicine, Sokoine University of Agriculture, Morogoro, Tanzania, personal communication, 2002; Boa et al., 2001). Farmers in both locations report allowing their pigs to roam about scavenging for food especially in the postharvest period and many respondents noted the presence of epileptics and tapeworm carriers in their villages. Currently no surveys on human cysticercosis/taeniosis have been undertaken in Tanzania and there are no official reports of cases. The high numbers of porcine cases in various sites in the country indicate a large reservoir of human tapeworm carriers for infecting pigs as well as humans.

\subsection{Kenya}

In the 1960s the Kenyan Ministry of Agriculture reported several cases of porcine cysticercosis. A government ban on free-range pig keeping led to a decrease in reported cases in the urban and export slaughterhouses around Nairobi. However, it is very likely that at the smaller slaughter slabs, which are common in the rural areas, many cases 
of porcine cysticercosis went unnoticed or were detected but not recorded. Home slaughter of pigs with no inspection is common in rural areas of Kenya (S.M. Githigia, Faculty of Veterinary Medicine, University of Nairobi, Nairobi, Kenya, personal communication, 2002). In mid-2000 several cases of porcine cysticercosis were detected at Slaughter Slab near Nairobi and a subsequent investigation led to the finding that these $T$. solium-infected pigs had been imported from Uganda (S.M. Githigia, Faculty of Veterinary Medicine, University of Nairobi, Nairobi, Kenya, personal communication, 2002).

Smallholder pig keeping has become popular in particular in southwestern Kenya in areas bordering Uganda. In many of these areas pigs are being kept under extensive, free-range conditions in spite of legislation requiring confinement of pigs. A recent survey of 107 smallholder pigs of various ages in a community in Busia District of southwestern Kenya indicated that 14\% (15/107) had $T$. solium cysticerci evident in their lingual muscles. Interviews of Kenyan pig farmers in 48 households revealed that $98 \%$ allow their pigs to roam free range while only $2 \%$ tether their pigs (Githigia et al., 2002). In another survey of 300 pigs in South Nyanza District (bordering Lake Victoria), the prevalence by lingual palpation was found to be $10 \%$. Most of the residents allowed their pigs to roam freely and also had knowledge of themselves or others in the community having tapeworm infections. Most homesteads lack toilets and the few that have do not always use them. Two cases of human neurocysticercosis have been recorded recently in Kenya, in Kakamega District and Nairobi hospital, respectively. Both cases had evidence of cysts in the brain and one case had a cyst in the eye (Renato F. Ruberti, Nairobi Neurological Clinic, Nairobi Hospital, Nairobi, Kenya, personal communication, 2002). According to the annual reports of the Kenyan Ministry of Health, the prevalence of human taeniosis in rural areas is estimated to be $2 \%$. However, this figure is higher in some areas. Hospital records from Busia District showed a prevalence between 4 and $10 \%$ in one division notably where free-range pig keeping is common (Githigia et al., 2002).

\subsection{Uganda}

According to the 1994 livestock census the pig population in Uganda is estimated to be 1.4 million, the highest in Eastern Africa, and shows an annual increase of $10 \%$. No extensive or structured studies on porcine cysticercosis have been conducted in Uganda, however limited preliminary surveys in 1998 and 1999 indicated a prevalence of 1.2 and $0.12 \%$, respectively, and suggested that most pig carcasses condemned because of cysticercosis came from rural areas such as Lira, Apac and Nakasongola Districts. This rather low reported prevalence from slaughterhouses is probably due to the screening process instituted by the pig traders whereby they conduct pre-purchase lingual examination on pigs in the rural areas so that only lingual negative pigs are brought to the only facility available for slaughtering pigs (Wambizi slaughterhouse in Kampala). This hypothesis is supported by the observation from a limited rural survey conducted in 1999 in Moyo (extreme north of Uganda) in which 34$45 \%$ of the pigs slaughtered in selected villages were found to be infected (Anyanzo, 1999). More recently, Kisakye and Masaba (2002) reported on a post-mortem survey of pigs slaughtered in Kampala. During a two-month period 297 pig carcasses were examined for cysticercosis. Most of the pigs surveyed (214) came from districts of the central region of Uganda including Kampala, Masaka, Mpigi and Mubende while 83 pigs came from the rural, northern district of Lira. None of the pigs originating from central region districts were found to be positive whereas 28 of the pigs coming from Lira were infected with $T$. solium cysts. Thus, overall $9.4 \%$ of the pigs surveyed were found positive with $33.7 \%$ of pigs coming from Lira infected. Only 6 of the positive pig carcasses were condemned while the others were released for consumption as they were deemed to have low intensities of infection though the authors note that if national meat inspection regulations had been strictly followed (i.e. condemnation if more than 7 cysts found at inspection sites) then 20 carcasses should actually have been condemned. Interestingly, one of the positive sows was found to be pregnant with 8 foetuses at slaughter. 
Examination of these foetuses revealed that all 8 were infected with cysts of $T$. solium with 32 cysts recovered from one foetus (Kisakye and Masaba, 2002). Given the high porcine cysticercosis prevalence rates in areas of Kenya and Tanzania bordering Uganda and its large rural pig population, it may be anticipated that Uganda has one of the highest prevalence rates of cysticercosis in the region.

\section{Southern Africa}

\subsection{Zambia}

In Zambia pigs are mostly raised under extensive conditions in rural communities of the Eastern and Southern Provinces. Many of the pigs raised in Southern Province are transported to Lusaka for sale, slaughter and consumption while those in Eastern Province are barred from export to other parts of the country due to concerns about the spread of African Swine Fever. Abattoir records indicate that six of Zambia's nine provinces have reported cases of porcine cysticercosis. Routine meat inspection of 1316 pigs at a slaughter slab in Lusaka that originated from Southern Province showed that $20.6 \%$ of the slaughtered pigs had cysticercosis. An enzyme-linked immunosorbent assay (ELISA) for the detection of circulating antigen (Ag-ELISA) performed on 874 pigs from the same abattoir indicated that $56.6 \%$ were seropositive (Phiri et al., 2001). Preliminary field surveys revealed that $8(8.2 \%)$ out of 98 pigs from Southern Province and $8(5.2 \%)$ out of 151 pigs from Eastern Province were positive for cysticercosis by tongue palpation. In the same survey, using the Ag-ELISA, 20 (20.8\%) and 14 $(9.3 \%)$ pigs tested positive in Southern and Eastern Provinces, respectively (Phiri et al., 2002). Community surveys for cysticercosis are now being conducted in both Southern and Eastern Provinces. There are recent reports from Lusaka hospitals of human patients with cysticercosis diagnosed from subcutaneous nodules, however, these reports are as yet not substantiated. Also, studies have indicated that epilepsy is responsible for a significant burden of disease in rural Zambia.
Some evidence suggests that epilepsy is underreported, under recognised, and under treated in this population (Birbeck, 2000). The possible causative role of cysticercosis in epilepsy in Zambia needs to be investigated.

\subsection{Zimbabwe}

In Zimbabwe, pigs are either raised intensively in commercial farms or kept extensively by smallholders in rural communities where the sanitation is poor. Most of the pigs from the smallholder sector are sold at informal markets where meat inspection services are nonexistent. In the 1960s and 1970s Robinson (1978) found the prevalence of porcine cysticercosis to be rather low, with a decreasing trend from $1.2 \%$ in 1968 to $0.48 \%$ in 1975. The level of infection was higher in freerange pigs $(4.26 \%)$ than in confined pigs, in which the prevalence was negligible $(0.03 \%)$. Recent reports of cysticercosis cases from slaughterhouses in the western region around Bulawayo (Matebeleland) revealed the problem to be serious in pigs coming from non-commercial sources in rural, communal areas. In 1995, the prevalence of porcine cysticercosis in this region was $2.7 \%$, whereas in the first half of 1999 it had increased to $28.6 \%$ (S. Mukaratirwa, Faculty of Veterinary Medicine, University of Zimbabwe, Harare, Zimbabwe, personal communication, 2000). In recent retrospective studies, the overall mean prevalence of porcine cysticercosis in Zimbabwe was found to be $0.34 \%$, but this figure is deemed biased as it is based on official abattoir records (Matenga et al., 2002).

In humans, calcified cysticerci are not uncommon incidental findings on chest or limb X-rays and neurocysticercosis is an occasional diagnosis at the time of surgery for intra-cranial or spinal lesions (Rachman, 1970). A study in Bulawayo reported calcified cysticerci in $11 \%$ of patients presented with seizures in whom thigh X-rays were taken (Rachman, 1970). Mason et al. (1992) reported a prevalence of anticysticercal antibodies of $12 \%$ in patients with signs and symptoms compatible with neurocysticercosis. The prevalence was higher in men (18\%) than in women (7\%). Ndhlovu (1997) reported an uncommon 
presentation of cysticercosis that manifested as a sudden death.

\subsection{Mozambique}

In Mozambique, abattoir records indicate that porcine cysticercosis is present in all provinces of the country. A sero-prevalence study in 11 districts of rural Tete Province showed that $15 \%$ of 387 pigs were sero-positive with a district range of 6.5$33.3 \%$ using an antibody-detecting ELISA based on purified cyst fluid antigen (fraction 17A) (Afonso et al., 2001). Vilhena and Bouza (1994) conducted a cross-sectional sero-epidemiological study in humans in Tete City and found that 32 human sera out of $157(20 \%)$ were positive by ELISA. Vilhena et al. (1999) carried out a similar study in the Central Hospital in Maputo and found a rate of $12.2 \%$ sero-positive (59 out of 489). The first clinical case of neurocysticercosis was reported at Maputo Central Hospital in 1999 (Santos et al., 1999).

\subsection{South Africa}

South Africa has the largest number of pigs (most being raised under commercial conditions) in southern Africa, and human cysticercosis has been recognised as a problem in the country for many decades. An extensive survey conducted in 1937 in 67 slaughterhouses in different areas of the country indicated a prevalence of porcine cysticercosis of 0.5 to $25.07 \%$ (Viljoen, 1937). In 1965, Heinz and MacNab (1965) reported that the average percentage of incidence of porcine cysticercosis reported at slaughterhouses around the country managed by the South African Meat Board ranged from 0 to $9.1 \%$ with a total of $1.7 \%$ of 28242 inspected pigs infected whereas the noncontrolled slaughter facilities in Umtata, Eastern Cape Province, reported an incidence greater than $10 \%$. Surprisingly there have apparently not been further epidemiological studies conducted on porcine cysticercosis in spite of strong evidence indicating that $T$. solium is an important pathogen of poor, black South Africans. During the past three decades several hospital surveys utilising serological and/or radiological diagnostic techni- ques have indicated that $28-50 \%$ of epileptics, predominantly black and including many children, were positive for cysticercosis (reviewed by Mafojane et al., in press, van As and Joubert, 1991; Campbell and Farrell, 1987; Naidoo et al., 1987; Thomson et al., 1984). Human cysticercosis appears to be most prevalent in Eastern Cape Province particularly in the poor, former black homeland, rural areas of Ciskei and Transkei, where pigs are allowed to roam freely and sanitation facilities are inadequate or nonexistent. The only community-based epidemiological studies conducted in these areas have involved children where surveys have indicated that $2.5-5.5 \%$ of Transkei children $(n=2088)$ were serologically positive for cysticercosis (Shasha and Pammenter, 1991; Pammenter et al., 1987). In addition to the surveys of rural inhabitants, a small hospital survey of urban black South Africans $(n=230)$ indicated a prevalence of $7.4 \%$ suggesting that urban dwellers are also at risk of infection with cysticercosis (Sacks and Berkowitz, 1990). An interesting and potentially life-threatening source of cysticercosis infections is from concoctions prepared by traditional healers to which are added tapeworm segments (Joubert and Evans, 1997).

\section{Conclusions}

Trends indicate that pig keeping and pork consumption are growing dramatically in the ESA region. Pig keeping in the region is predominantly of the smallholder, traditional type, characterised by a free-range management system. Pigs are slaughtered mainly in the backyard or at illegal slaughter slabs where no meat inspection is performed. Data presented in this review as summarized in Table 1, clearly show that porcine cysticercosis is widely prevalent in the region, becoming an obstacle to smallholder farmers wanting to market their pigs.

Several of these studies utilised diagnostic techniques of low sensitivity (e.g. lingual examination) suggesting that the prevalence figures obtained are probably an underestimation. This in turn suggests that human neurocysticercosis and cysticercosis/ taeniosis are most likely a serious health risk in 
Table 1

Results of prevalence studies on porcine cysticercosis conducted in Eastern and Southern Africa countries

\begin{tabular}{|c|c|c|c|c|c|}
\hline Country & $\begin{array}{l}\text { Porcine cysticercosis } \\
\text { prevalence }(\%)\end{array}$ & $\begin{array}{l}\text { Number of pigs } \\
\text { surveyed }\end{array}$ & $\begin{array}{l}\text { Type of } \\
\text { survey }^{a}\end{array}$ & Area surveyed & Reference \\
\hline Tanzania & $\begin{array}{l}0.04-4.9 \\
4.5-37.7 \\
3.2-46.7 \\
0-26.9\end{array}$ & $\begin{array}{l}45794 \\
83 \\
770 \\
1789\end{array}$ & $\begin{array}{l}P \\
P \\
L \\
L\end{array}$ & $\begin{array}{l}\text { Mbulu District } \\
\text { Northern highlands } \\
\text { Mbulu District } \\
\text { Southern highlands }\end{array}$ & $\begin{array}{l}\text { Nsengwa }(1995)^{\mathrm{b}} \\
\text { Boa et al. (1995) } \\
\text { Ngowi (1999) } \\
\text { Boa (2002) }\end{array}$ \\
\hline Kenya & $10.0-14.0$ & 407 & $\mathrm{~L}$ & Busia and South Nyanza Districts & Githigia et al. (2002) \\
\hline Uganda & $\begin{array}{l}33.7-44.5 \\
0-33.7^{\mathrm{c}}\end{array}$ & $\begin{array}{l}600 \\
297\end{array}$ & $\begin{array}{l}\mathrm{P} \\
\mathrm{P}\end{array}$ & $\begin{array}{l}\text { Moyo District } \\
\text { Central and Northern Districts }\end{array}$ & $\begin{array}{l}\text { Anyanzo (1999) } \\
\text { Kisakye and Masaba (2002) }\end{array}$ \\
\hline Zambia & $\begin{array}{l}20.6-56.6 \\
8.2-20.8\end{array}$ & $\begin{array}{l}1316 \\
249\end{array}$ & $\begin{array}{l}\text { S, P } \\
\text { L, S }\end{array}$ & $\begin{array}{l}\text { Lusaka } \\
\text { Eastern and Southern Provinces }\end{array}$ & $\begin{array}{l}\text { Phiri et al. (2001) } \\
\text { Phiri et al. (2002) }\end{array}$ \\
\hline Zimbabwe & $\begin{array}{l}0.03-4.3 \\
2.7-28.6\end{array}$ & $\begin{array}{l}1000000 \\
99525\end{array}$ & $\begin{array}{l}\mathrm{P} \\
\mathrm{P}\end{array}$ & $\begin{array}{l}\text { National } \\
\text { Western Region }\end{array}$ & $\begin{array}{l}\text { Robinson (1978) } \\
\text { Matenga et al. (2002) }\end{array}$ \\
\hline Mozambique & $6.5-33.3$ & 387 & $\mathrm{~S}$ & Tete Province & Afonso et al. (2001) \\
\hline South Africa & $\begin{array}{l}0.5-25.1 \\
0-9.1\end{array}$ & $\begin{array}{l}>100000 \\
28242\end{array}$ & $\begin{array}{l}\mathrm{P} \\
\mathrm{P}\end{array}$ & $\begin{array}{l}\text { National } \\
\text { National }\end{array}$ & $\begin{array}{l}\text { Viljoen (1937) } \\
\text { Heinz and MacNab (1965) }\end{array}$ \\
\hline
\end{tabular}

a $\mathrm{P}=$ post-mortem, $\mathrm{L}=$ lingual examination, $\mathrm{S}=$ serological.

b Survey conducted from 1985-1989.

${ }^{\mathrm{c}}$ Eight foetuses from a positive slaughtered pregnant sow were all found to be infected with cysticercosis.

rural areas of the regions where pigs are raised as well as urban centers where pork consumption is popular. More, higher quality data needs to be collected concerning the extent of the disease, its epidemiology including risk factors and its economic and public health impact before appropriate and sustainable control measures can be formulated.

One of the most striking findings during this review has been the almost complete absence of recent data on human cysticercosis in the ESA countries (aside from South Africa) and the general lack of knowledge of the $T$. solium cysticercosis-taeniosis complex among medical and veterinary doctors, healthcare workers, agricultural extension workers, policymakers and the general public. The high prevalence of cysticercosis in pigs strongly suggests that many people are carriers of the pig tapeworm and consequently contaminate their direct environment with eggs containing oncospheres that are infective for both humans and pigs, thereby maintaining the life cycle. In regions where cysticercosis in pigs is common, human cysticercosis and epilepsy prevalence are also usually high as shown by results from other endemic areas in Latin America and other African countries (Diaz et al., 1992; Newell et al., 1997; Sciutto et al., 2000). Therefore, there is an urgent need to collect baseline data on human cysticercosis and its possible linkage with epilepsy in the ESA region for a better understanding of the local epidemiology and transmission risks.

The evidence concerning $T$. solium in the ESA region provided by the few prevalence studies conducted thus far should provide the impetus for further research in the region on human $T$. solium taeniosis and cysticercosis and cysticercosis in pigs. In countries where there is enough evidence concerning the presence of porcine cysticercosis, extension programmes, community education and other prevention and control initiatives may be started while further needed research on cysticercosis and taeniosis is being conducted. Of importance is the need for socioeconomic studies on the issue in addition to more epidemiological research in order to prepare for a more holistic approach to the factors involved and successfully apply the solutions associated with porcine cysticercosis. 
In order to be successful research, surveillance and control activities will be dependent on the presence of proper infrastructure in the ESA region. Technology and equipment for diagnosing taeniosis and cysticercosis in both humans and pigs will need to be acquired and regional reference centers established to assist with surveillance and control activities as well as training of those to conduct the activities. In order for efforts to be effective and sustainable, policymakers at the local, regional and national levels will need to play an active role as stakeholders ensuring that needed legislation concerning surveillance, prevention and control of $T$. solium is enacted as well as implemented. The ESA regional action plan for $T$. solium surveillance and control formulated at the Arusha, Tanzania workshop on cysticercosis/taeniosis in 2002 will be helpful for providing guidance in the future with regard to meeting the challenges presented by this important disease of agricultural and public health importance.

\section{References}

Afonso, S.M.S., Neves, L., Afonso, C.M.C.S., Nota, A., Vilhena, M., Ito, A., 2001. Cysticercosis cellulosae in Tete Province, Mozambique. Proceedings of the Workshop on Human Helminth Infections 'Future Research Foci', 5-9 March 2001, Lusaka, Zambia, pp. 32.

Anonymous, 1995. PAHO/WHO Informal consultation on the taeniosis/cysticercosis complex. Brazil, pp. 20.

Anyanzo, T., 1999. Prevalence of Cysticercosis cellulosae in three sub-counties of Moyo County, Moyo District, Uganda. Faculty of Medicine, Makerere University, Kampala, Uganda. Bachelor of Veterinary Medicine special project report.

Boa, M.E., Bøgh, H.O., Kassuku, A.A., Nansen, P., 1995. The prevalence of Taenia solium metacestodes in pigs in northern Tanzania. Journal of Helminthology 69, 113-117.

Boa, M.E., Jessen, O.L., Kassuku, A.A., Willingham, A.L., 2001. Proceedings of the 18th International Conference of the World Association for the Advancement of Veterinary Parasitology, 26-30 August 2001, Stresa, Italy, A10.

Birbeck, G.L., 2000. Seizures in rural Zambia. Epilepsia 41, 277-281.

Campbell, G.D., Farrell, V.J.R., 1987. Brain scans, epilepsy and cerebral cysticercosis. South African Medical Journal $72,885-886$.

Cysticercosis Working Group in Peru, Diaz, F., Garcia, H.H., Gilman, R.H., Gonzales, A.E., Castro, M., Tsang, V.C.W., Pilche, J.B., Vasquez, L.E., Lescano, M., Carcamo, C.,
Madico, G., Miranda, E., 1992. Epidemiology of taeniasis and cysticercosis in a Peruvian village. American Journal of Epidemiology 135, 875-882.

FAO (Food and Agriculture Organization) of the United Nations, 2002. FAOSTAT: the statistical database of FAO. Available from: http://www.fao.org/waicent/portal/ statistics_en.asp

Githigia, S.M., Murekefu, K., Ngesa, S.M., Otieno, R.O., Kahai, R., 2002. The prevalence of porcine cysticercosis and risk factors in Busia District, Kenya. Proceedings of the 11th Annual meeting of ENRECA Livestock Helminths Research Project in Eastern and Southern Africa, 6-9 June 2002 Lusaka, Zmbia.

Heinz, H.J., MacNab, G.M., 1965. Cysticercosis in the Bantu of Southern Africa. South African Journal of Medical Science 30, 19-31.

Joubert, J.J., Evans, A.C., 1997. Current status of food-borne parasitic zoonoses in South Africa and Namibia. Southeast Asian Journal of Tropical Medicine and Public Health 28, $7-10$.

Kisakye, J.J.M., Masaba, S.C., 2002. Cysticercus cellulosae in pigs slaughtered in and around Kampala City. Uganda Journal of Agricultural Sciences 7, 23-24.

Mafojane, N.A., Appleton, C.C., Krecek, R.C., Michael, L.M., Willingham III, A.L. The current status of neurocysticercosis in Eastern and Southern Africa. Acta Tropica 87, $25-$ 33 (this issue).

Mason, P., Houston, S., Gwanzura, L., 1992. Neurocysticercosis: experience with diagnosis by serology and computerised tomography in Zimbabwe. Central African Journal of Medicine 38, 149-154.

Matenga, E., Mukaratirwa, S., Willingham A.L., 2002. Prevalence of porcine cysticercosis and hydatidosis in slaughtered animals in southwestern Zimbabwe: a retrospective study. Proceedings of the 11th Annual Meeting of ENRECA Livestock Helminths Research Project in Eastern and Southern Africa, 6-9 June 2002, Lusaka, Zambia.

Naidoo, D.V., Pammenter, M.D., Moosa, A., van Dellen, J.R., Cosnett, J.E., 1987. Seventy black epileptics. Cysticercosis, computed tomography and electro-encephalography. South African Medical Journal 72, 837-838.

Ndhlovu, C.E., 1997. An uncommon presentation of cysticercosis. Central African Journal of Medicine 43, 207-209.

Newell, E., Vyungimana, F., Geerts, S., Van Kerckhoven, I., Tsang, V.C.W., Engels, D., 1997. Prevalence of cysticercosis in epileptics and members of their families in Burundi. Transactions of the Royal Society of Tropical Medicine 91, 389-391.

Ngowi, H.N., 1999. Endoparasites of zoonotic importance in pigs in Mbulu District, Tanzania. Faculty of Veterinary Medicine, Sokoine University of Agriculture (SUA), Morogoro, Tanzania. Masters Thesis.

Nsengwa, G.R.M., 1995. Porcine cysticercosis in northern Tanzania between 1985 and 1988. Tanzania Veterinary Journal 15, 9-11.

Pammenter, M.D., Rossouw, E.J., Dingle, C.E., 1987. Serological detection of cysticercosis in two rural areas of South 
Africa. Transactions of the Royal Society of Tropical Medicine and Hygiene 81, 242-244.

Phiri, I.K., Dorny, P., Gabriel, S., Willingham, A.L., Speybroeck, N., Vercruysse, J., 2002. The prevalence of porcine cysticercosis in Eastern and Southern Provinces of Zambia. Veterinary Parasitology 108, 31-39.

Phiri, I.K., Gabriel, S., Dorny, P., Willingham, A.L., Vercruysse, J., 2001. Cysticercosis in Zambia. Proceedings of the 18th International Conference of the World Association for the Advancement of Veterinary Parasitology, 26-30 August 2001, Stresa, Italy, A9.

Rachman, I., 1970. Epilepsy in an African hospital. Central African Journal of Medicine 16, 201-204.

Robinson, J.T.R., 1978. Some epidemiological, economic and legislative aspects of bovine and porcine cysticercosis in Rhodesia. Masters Thesis.

Sacks, L.V., Berkowitz, I., 1990. Cysticercosis in an urban black South African community; prevalence and risk factors. Tropical Gastroenterology 11, 30-33.

Santos, M., Vilhena, M., Prazeres, M., Tsang, V.C.W., Torgal, J., 1999. The first documental clinical case in Mozambique. Acta Parasitológica Portiguesa 5.

Sarti, E., Schantz, P.M., Plancarte, A., Wilson, M., Gutierrez, I.O., Lopez, A.S., Roberts, J., Flisser, A., 1992. Prevalence and risk factors for Taenia solium taeniosis and cysticercosis in humans and pigs in a village in Morelos, Mexico. American Journal of Tropical Medicine and Hygiene 46, $677-685$.
Sciutto, E., Fragoso, G., Fleury, Laclette, J.P., Sotelo, J., Aluja, A., Vargas, L., Larralde, C., 2000. Taenia solium disease in human and pigs: an ancient parasitosis disease rooted in developing countries and emerging as a major health problem of global dimensions. Microbes and Infection 2, 1875-1890.

Shasha, W., Pammenter, M.D., 1991. Sero-epidemiological studies of cysticercosis in school children from two rural areas of Transkei, South Africa. Annals of Tropical Medicine and Parasitology 85, 349-355.

Thomson, A.J., de Villiers, J.C., Moosa, A., Van Dellen, J., 1984. Cerebral cysticercosis in children in South Africa. Annals of Tropical Paediatrics 4, 67-77.

van As, A.D., Joubert, J., 1991. Neurocysticercosis in 578 black epileptic patients. South African Medical Journal 80, $327-$ 328.

Vilhena, M., Bouza, M., 1994. Serodiagnostico da cistecercose humana na Cidade de Tete-Moçambique. Revista Medica de Mocambique 5, 6-9.

Vilhena, M., Santos, M., Torgal, J., 1999. Seroprevalence of human cysticercosis in Maputo, Mozambique. American Journal of Tropical Medicine and Hygiene 61, 59-62.

Viljoen, N.F., 1937. Cysticercosis in swine and bovines, with special reference to South African conditions. Onderstepoort Journal of Veterinary Science and Animal Husbandry 9, 337-570.

White, A.C., Jr., 2000. Neurocysticercosis: update on epidemiology, pathogenesis, diagnosis and management. Annual Reviews Medicus 51, 187-206. 